\title{
Análise Comparativa da Argumentação no Discurso Prévio à Campanha Eleitoral de Aécio Neves e Dilma Rousseff
}

\section{Comparative Analysis of the Argument in the Previous Discourse to the Election Campaign Aecio Neves and Dilma Rousseff}

Beatriz dos Santos Clemente Machado ${ }^{1}$

Rede Estadual de Ensino de Minas Gerais, Viçosa, Minas Gerais / Brasil

beatrizmachado1@yahoo.com.br

Mônica Santos de Souza Melo

Universidade Federal de Viçosa, Viçosa, Minas Gerais / Brasil

monicassmelo@yahoo.com.br

Resumo: No contexto atual, o discurso político volta-se para a busca de uma troca social visando à demonstração da capacidade do político de dizer e fazer. Para isso, o político engaja-se num projeto de construção da imagem de si, e nota-se um grande trabalho por parte dele para fazer reconhecer-se socialmente por meio de um ethos de honestidade e de credibilidade relacionado ao empreendedorismo, ao trabalho e ao sucesso. Com o intuito de realizar um estudo comparativo da argumentação e da busca pelo ethos nos discursos prévios à campanha eleitoral de Aécio Neves e de Dilma Rousseff no ano de 2014, esta pesquisa propõe compreender como a imagem de si mesmo se projeta no discurso político durante o processo de enunciação e permite a coconstrução de uma identidade por meio do discurso. Este artigo se baseia na Teoria Semiolinguística de Charaudeau (2004, 2005, 2006, 2012a, 2012b) por meio dos Modos de Organização do Discurso e suas

\footnotetext{
${ }^{1}$ Mestre em Letras: Estudos Linguísticos pela Universidade Federal de Viçosa (UFV), professora da rede estadual de ensino de Minas Gerais.

${ }^{2}$ Professora Associada III do Departamento de Letras da UFV. Bolsista de Produtividade em Pesquisa do CNPq, processo 304833/2014-2. .
} 
concepções sobre o discurso político. Busca-se, dessa maneira, a partir de artigos de Aécio Neves publicados no portal Folha e entrevistas de Dilma Rousseff concedidas ao programa Café com a Presidenta, disponíveis on-line, analisar a estruturação do processo de semiotização da linguagem, verificando-se as estratégias adotadas para a constituição do ethos argumentativo vinculado aos imaginários sociodiscursivos associados aos futuros candidatos. Este estudo pretende, assim, elucidar algumas questões que envolvem o discurso político, como os espaços de estratégias e de restrições do contrato de comunicação e os papéis sociais dos participantes dessa forma particular de enunciação.

Palavras-chave: Análise do Discurso; aspectos políticos; Semiolinguística.

Abstract: In the present context, the political discourse turns to the search for a social change aimed at demonstrating the politician's ability to say and do. For this, the politician engages in a project of construction of the image of itself, and noticed a big job to recognize up socially through an ethos of honesty and credibility related to entrepreneurship, work and success. In order to conduct a comparative study of argumentation and the search for ethos in the previous speech to the election campaign Aecio Neves and Dilma Rousseff in 2014, this research aims to understand how the image of himself projects in political discourse during the enunciation process and allows the co-construction of an identity through discourse. This article is based on Semiolinguistics Theory Charaudeau (2004, 2005, 2006, 2012a, 2012b) through the Organization Modes of Discourse and his views on the political discourse. Seeks, in this way, from Aécio Neves articles on the portal Folha and interviews Dilma Rousseff granted Café com a Presidenta program, available online, analyze the structure of language semiotization process, checking the strategies adopted to the constitution of the argumentative ethos linked to sociodiscursivos imaginary associated with future candidates. It is intended, therefore, to elucidate some issues involving the political discourse, as the spaces of strategies and communication contract restrictions and social roles of the participants of this particular form of enunciation.

Keywords: Discourse Analysis; politicians aspects; Semiolinguistics.

Recebido em: 26 de junho de 2016. Aprovado em: 27 de outubro de 2016. 


\section{Introdução}

Pensando em analisar a constituição do discurso político, este artigo faz o recorte de uma pesquisa mais ampla, baseada na Teoria Semiolinguística e tem como objetivo contribuir para o trabalho em sala de aula na busca pela formação de cidadãos críticos e autônomos uma vez que o estudo a que nos propomos se relaciona com as atividades de leitura e compreensão de textos e com a capacidade de análise do discurso a partir do contexto de produção, circulação e recepção. No presente trabalho de pesquisa, procuramos contemplar, especificamente, o processo de produção e circulação dos textos analisados, buscando uma reflexão sobre essa complexa relação entre o que se diz, como se diz e para quem se diz.

Buscamos, nesse sentido, desenvolver um estudo comparativo sobre a argumentação nos discursos prévios à campanha eleitoral de Aécio Neves e Dilma Rousseff por considerar que esses discursos são pertinentes para o estabelecimento de uma relação de influência social e da constituição da identidade social dos políticos. O corpus vincula-se ao primeiro semestre de 2014, momento em que vivemos um grande debate social a respeito de política, e tem seu interesse acentuado pelo fato de se tratar de um ano eleitoral em que os políticos, embora em período pré-eleitoral, já se mostram em processo de campanha para o cargo de presidente da república.

Embora não pertençam ao mesmo gênero (artigo de opinião $\mathrm{x}$ entrevista) e sejam aparentemente muito diferentes, os dois materiais apresentam características em comum: são produzidos por dois "presidenciáveis" em situações aparentemente não eleitoreiras, mas que, indiretamente, são usadas para esse fim. Do senador Aécio Neves, tomamos como instrumento de pesquisa suas publicações de coluna de jornal no portal on-line da Folha de S. Paulo publicados semanalmente na seção "Opinião". Da presidente Dilma Rousseff, também pré-candidata (nesse caso, à reeleição), selecionamos as entrevistas concedidas ao programa Café com a Presidenta, disponíveis on-line. O corpus se situa entre dezembro de 2013 e o primeiro trimestre de 2014.

Nosso trabalho se baseia nos pressupostos da Teoria Semiolinguística do Discurso na abordagem específica proposta por Charaudeau (2001, 2004, 2005, 2006, 2012a, 2012b) que diz respeito à dimensão transdisciplinar da problemática semiolinguística e de 
teorias argumentativas de Aristóteles; Perelman e Olbrechts-Tyteca (2005), dentre outros, relacionando-os aos fenômenos psicológicos e sociais pertinentes ao contrato de comunicação em questão. No presente trabalho esboçamos, na primeira seção, uma breve noção sobre as teorias argumentativas, a partir dos pressupostos teóricos que deram suporte à pesquisa. Na segunda seção, apresentamos a categorização dos gêneros discursivos do corpus e, na terceira seção, procedemos a análise dos dados do corpus. Por fim, apresentamos conclusões da pesquisa realizada.

\section{A teoria Semiolinguística e teorias argumentativas: imagens no discurso político}

Nesta seção, trazemos alguns pressupostos da Teoria Semiolinguística do Discurso, desenvolvida por Charaudeau, com a finalidade de expor alguns aspectos que nortearam o presente estudo, como a questão da encenação do discurso político envolvendo os sujeitos da linguagem num fenômeno psicológico e social e numa relação contratual. Expomos, também, algumas teorias argumentativas que serviram de base para o pensamento atual da Análise do Discurso e da Argumentação na Semiolinguística. Refletimos, ainda, mais especificamente, sobre a argumentação no discurso político, interligada à busca de construção de uma imagem de si por parte dos políticos para conquistar seu interlocutor.

\subsection{A teoria semiolinguística do discurso}

A Análise do Discurso Francesa (ADF) fundada na França, a partir das reflexões do filósofo Michel Pêcheux em conjunto com outros pesquisadores, se baseia em estudos das configurações verbais por meio de suas condições sociais de produção, levando-se em conta a significação e o modo de produção dos discursos. Podemos afirmar que a Análise do Discurso hoje, de um modo geral, engloba várias correntes de análises entrecruzadas, como assinala Machado (2001). Novos conceitos foram surgindo e, nos últimos anos, a Análise do Discurso vem contribuindo bastante para os estudos no sentido de uma nova concepção do discurso em que só é possível a ideia de sujeito como histórico, social e cultural.

Charaudeau desenvolveu a Teoria Semiolinguística que foi divulgada, a partir de 1983, por meio do livro Langage et Discours, em que a linguagem passa a ser vista como "veículo social de comunicação" 
(MACHADO, 2007, p. 115). A Semiolinguística, assim, traz uma nova perspectiva para a $\mathrm{AD}$, tendo em vista que o enunciado deve ser analisado como um conjunto que envolve representações sociais perpassadas em diferentes suportes, situações de comunicação e gêneros distintos. Charaudeau (2012a) desenvolve o conceito de que o ato de linguagem não pode ser analisado apenas por sua configuração verbal, mas, acima de tudo, deve ser considerado como parte de um jogo em que o sujeito falante encena sua participação de modo a produzir determinados sentidos.

A análise semiolinguística, dessa maneira, procura problematizar essa relação, por meio da compreensão das circunstâncias de produção e os atos de linguagem para a interpretação dos sentidos dos enunciados, conforme explica Melo (2007). O relacionamento do mundo significado depende dos papéis desempenhados pelos sujeitos envolvidos num contexto, de acordo com os princípios de alteridade, pertinência, influência e regulação, de forma solidária entre eles (CHARAUDEAU, 2005). Sua identidade não é fixa; está, ao contrário, em constante reconstrução no discurso. A Semiolinguística, dessa maneira, tem como princípios fundamentais a noção do texto em seu contexto para construir formas de comunicação e representação do mundo.

A base da Semiolinguística é a ação comunicativa e, entendendo que toda ação comunicativa envolve uma situação de comunicação entre parceiros determinados por uma identidade (psicológica ou social), percebemos que essa ação está ligada a um contrato de comunicação. De acordo com Charaudeau (2012a), comunicar é proceder a uma mise en scène, ou seja, todos os nossos atos de linguagem se fazem numa encenação, a partir de dados de nossas condições de seres históricos e sociais, em determinadas situações, em determinado espaço e tempo. Por isso, de acordo com Charaudeau (2012a), o processo de comunicação decorre de uma dupla intencionalidade em que o sentido implícito se relaciona com o sentido explícito na construção da significação.

Nessa relação, tanto o EUc (Sujeito comunicante) como o TUi (Sujeito interpretante) participam do processo de interpretação, sendo que, para a efetivação do discurso, algumas restrições fazem parte em função das circunstâncias de sua produção e interpretação, como condições para a comunicação. A noção de contrato de discurso (CHARAUDEAU, 2012a) pressupõe um acordo entre os indivíduos de um mesmo grupo a fim de se fazer uma proposição sobre o EU e o TU numa relação de reciprocidade. 
Assim, a encenação argumentativa revela uma característica do ato de linguagem que é o de estar em constante exercício de busca de acordo e ajuste no discurso. Melo (2007, p. 109) assinala que esse contrato compreende "uma obrigação convencional de cooperação, que liga os parceiros numa finalidade de dizer e que atribui a eles determinados papéis linguageiros". Em consequência dessa relação contratual, estratégias discursivas são utilizadas através de escolhas linguísticas para se alcançar a finalidade de identificar o destinatário e, de alguma forma, influenciá-lo.

\subsection{Argumentação e teorias argumentativas}

Desde a Antiguidade, através dos estudos principalmente da Lógica, da Ética e da Retórica de Aristóteles, busca-se compreender a argumentação, a partir de sua relação de persuasão e convencimento a fim de promover uma ação. Esse princípio da argumentação se vincula à Oratória, compreendida como uma prática metódica a ser ensinada de uso da eloquência. Mais tarde, os estudos de Perelman, baseados em Aristóteles, deram origem à Nova Retórica, em que se buscou a reflexão sobre o poder da palavra na sua dimensão de troca social, incluindo a dialética e rompendo com a visão de exposição fora da inter-relação social. Mais recentemente, Charaudeau também se dedica ao estudo da argumentação considerando-a como uma atividade discursiva envolvendo sujeitos psicossociais.

Aristóteles (2010) desenvolveu um conceito de retórica que transcendeu os estudos sofísticos a partir de critérios de prova, mas compartilhava a definição da Retórica como a arte do verossímil, aquilo em que se crê. Seus estudos contribuíram significativamente para o pensamento moderno ao estabelecer a relação entre orador e o auditório como essencial e ao desenvolver uma teoria de gêneros, baseada nos lugares-comuns (topói), relacionados aos valores partilhados socialmente em um dado momento. Mais voltado para a técnica da argumentação no campo da Lógica e da Matemática, esse pensamento prevaleceu até o final do século XIX, quando a Retórica sofreu críticas severas como disciplina não científica e foi excluída do currículo de algumas universidades.

A Nova Retórica surge com Perelman e Olbrechts-Tyteca (2005) ao trazer uma nova teoria da argumentação segundo a qual há uma releitura dos conceitos da antiga retórica da argumentação. Perelman 
e Olbrechts-Tyteca compreendem o discurso como argumentação e deixam clara a sua posição contrária ao discurso reduzido ao cálculo da demonstração. Além disso, acrescentam a noção de justiça como base da argumentação por meio de uma tradição moral e ética (SOUZA, 2001). A argumentação para Perelman e Olbrechts-Tyteca (2005) não se assemelha a uma certeza, mas fundamentalmente à comunicação, diálogo e discussões. Uma das noções fundamentais de Perelman e OlbrechtsTyteca é a de que, para atingir a persuasão, o orador precisa ter em mente as teses admitidas por seu auditório.

Assim, na visão da Nova Retórica, o orador com um material indeterminado deve ter uma racionalidade e uma adaptação aos efeitos pretendidos. Os argumentos, se não puderem ser medidos por elementos calculáveis, deverão ser avaliados em função da justiça. O novo paradigma moderno da argumentação, desse modo, faz da linguagem o objeto singular das Ciências Humanas.

Charaudeau (2012a), ao propor o Modo de Organização Argumentativo, traz um modelo da argumentação em que o dispositivo argumentativo abrange uma tese a ser defendida e um quadro de problematização e de questionamento que envolve sentidos explícitos e implícitos. Os estudos de Charaudeau (2012a) demonstram sua afiliação aos conceitos da Nova Retórica, embora esta se afaste dos estudos psicológicos e sociológicos defendidos pelo autor.

Desse modo, Charaudeau explicita que toda relação argumentativa se compõe de pelo menos três elementos: uma asserção de partida (dado, premissa) $\rightarrow \mathrm{A} 1$, uma asserção de chegada (conclusão, resultado) $\rightarrow \mathrm{A} 2$, que deve ser aceita em decorrência da ação de partida, e uma (ou várias) asserção de passagem, que permite passar de uma a outra (inferência, prova, argumento), unindo A1 e A2 (CHARAUDEAU, 2012a). O ponto de vista psicossocial de Charaudeau coloca ênfase no processo subjetivo da argumentação enquanto ato individual de linguagem, ao mesmo tempo em que envolve um processo social de influência.

\subsection{O discurso político: perspectiva histórica}

O discurso político foi um dos primeiros objetos de interesse da Análise do Discurso, num contexto em que a Linguística passava por transformações, após a segunda Guerra Mundial. O tema política e a questão do poder, entretanto, têm sido discutidos desde a Antiguidade de 
Platão, Aristóteles, Kant e mais recentemente por Weber, Arendt, Foucault, Bordieu e Habermas, como lembra Charaudeau (2006). Voltando para a concepção do discurso político, a partir de sua compreensão como fenômeno político, Charaudeau (2006) traz uma inovação para o sentido da política, focalizando o discurso político dialogando com os pensadores antigos e várias disciplinas (Psicologia Social, Antropologia Social, Ciências Políticas, etc.). Como espaço de linguagem e ação, o discurso político se configura na troca social dos sujeitos numa relação de interdependência recíproca entre sujeitos (CHARAUDEAU, 2006).

O discurso político se configura, então, em duas dimensões: na legitimidade e na capacidade de atuar na esfera política. Consequentemente, a ação política determina a vida social ao mesmo tempo em que permite decisões coletivas. A partir de objetivos pré-definidos, toda ação se concretiza por um sujeito em posição de decisão, mesmo que a decisão seja coletiva. Por isso, segundo Charaudeau (2006), a política depende do discurso, e a instância política de realização da ação política utiliza argumentos da razão e da paixão para convencer os sujeitos de seus valores, num espaço de persuasão.

Todo o processo de encenação do discurso político se dá num espaço de restrições em que "as significações e os efeitos resultam de um jogo complexo de circulação e de entrecruzamentos dos saberes e das crenças que são construídos por uns e reconstruídos por outros" (CHARAUDEAU, 2006, p. 52). Os sujeitos do contrato de comunicação, segundo Charaudeau (2006), são definidos como "instâncias" em função de sua "finalidade comunicacional". Como entidade humana, cada sujeito ocupa o lugar de uma intencionalidade em função dos papéis que lhe são atribuídos.

Nessa perspectiva, Charaudeau (2006), distingue três lugares de fabricação do discurso político: um lugar de governança, um lugar de opinião e um lugar de mediação. Segundo o autor (2006), o lugar de governança é onde se encontra a instância política, juntamente com $a$ instância adversária. Já no lugar de opinião, encontra-se a instância cidadã e a instância midiática no lugar de mediação. Dessa maneira, cabe à instância política o poder de decisão e de ação com a finalidade de atingir legitimidade, autoridade e credibilidade. À instância cidadã, cabe julgar as propostas e ações impostas, escolher ou criticar os políticos. À instância midiática, por sua vez, cabe unir a instância política e cidadã, 
através da tecnologia que permite o atravessamento das informações de forma multidirecional.

Essas condições proporcionam a legitimidade e a credibilidade, sendo que as duas primeiras correspondem a condições relativas ao poder (reconhecimento do poder) que contribuem para a legitimidade e são pré-determinadas. Por outro lado, como a legitimidade é própria do sujeito e não deriva apenas do espaço externo (identidade psicossocial), mas também do espaço interno (comportamento linguageiro), a terceira condição garante a adequação entre esses espaços e confirma a credibilidade do sujeito.

Ao contrário, a credibilidade não é pré-determinada, mas construída num espaço externo (lugar de legitimidade) e espaço interno (lugar de credibilidade), a partir de negociações nas práticas sociais de uso da linguagem, "sem a qual, não obstante toda legitimidade que o sujeito possua pelo saber e/ou pelo poder será colocado em xeque o seu direito à palavra" (MENDES, 2001, p. 318, grifos do autor). Logo, o discurso político é representativo dessa relação dialética das práticas de linguagem, ou seja, o sujeito busca sua legitimação por meio da construção de sua credibilidade.

\section{$1.4 \mathrm{O}$ ethos discursivo na argumentação do discurso político}

A análise do ethos na argumentação ou das imagens construídas pelos sujeitos passou a despertar novamente o interesse de estudiosos nos últimos anos como procedimento discursivo pela sua multiplicidade de enfoques, levando a acepções distintas sobre a polissemia da argumentação, principalmente a partir das noções de Aristóteles, Perelman, Ducrot, Plantin, entre outros. Na sociedade brasileira atual, as representações dos políticos perante a sociedade estão cada vez mais caindo na incredibilidade e na descrença quanto à forma como agem e se comportam na política. Percebemos que a política tem se tornado um jogo de interesses e que a máscara que poderia ser um símbolo da identificação do político, passou a ser uma forma de esconder a realidade e enganar os cidadãos muitas vezes.

No âmbito da Semiolinguística, Charaudeau (2006), expandindo as noções de outros estudiosos, defende que o ethos constitui uma imagem transvestida do interlocutor com base naquilo que ele diz. Assim, o ethos resulta no "cruzamento de olhares. Olhar do outro sobre aquele que fala, 
olhar daquele que fala sobre a maneira como ele pensa que o outro vê" (CHARAUDEAU, 2006, p. 115). Charaudeau (2006) afirma que, para a construção dessa imagem ao olhar do outro, o sujeito apresenta-se com sua identidade psicológica e social de locutor, ao mesmo tempo em que se mostra mediante a identidade discursiva que ele constrói para si.

Por isso, consideramos o ethos como uma prova retórica, mas que, no escopo da semiolinguística, é considerada uma estratégia. Charaudeau (2006) alerta que o ethos não se liga tão somente à imagem do indivíduo, mas pode estar vinculado a um grupo no qual se configura o ethos coletivo, resultante de julgamentos realizados uns pelos outros, que se baseiam em traços de identidades. A noção de ethos para Charaudeau (2006), assim, está vinculada às identidades do sujeito. De acordo com o autor, o sujeito apresenta uma identidade social capaz de promover sua legitimidade de ser comunicante em decorrência do estatuto dos papéis que lhe são atribuídos pela situação comunicativa.

Nesse sentido, o ethos no discurso político é o resultado de um trabalho de entrecruzamento de imaginários populares por parte do sujeito enunciador, a fim de se atingir o maior número possível de adeptos ao seu discurso e, consequentemente, persuadir o destinatário em função de seus desejos e expectativas. Considerando-se o discurso político na mídia, nota-se a presença de uma atividade por parte dos sujeitos enunciadores, a partir das escolhas linguísticas e de seu objetivo comunicativo, para persuadir o leitor, a partir de mudanças na imagem dos sujeitos em função da substituição de certos elementos contextuais e situacionais por outros.

\section{Configuração do corpus: categorização dos gêneros artigo de opinião e entrevistas e as restrições do contrato de comunicação}

Nesta seção, voltamo-nos para a análise do corpus. Refletimos sobre alguns conceitos fundamentais para a compreensão do gênero na concepção da Semiolinguística e sobre as restrições do contrato de comunicação nas colunas de Aécio Neves no Portal Folha e nas entrevistas simuladas de Dilma Rousseff no Programa Café com a Presidenta. É preciso ressaltar que entendemos os gêneros na sua construção pelo sujeito por meio de representações sociais advindas da aprendizagem e experiência, sendo, portanto, um lugar de práticas sociais relativamente institucionalizadas e situacionais. 
A questão dos gêneros discursivos vem sendo abordada ao longo dos anos por inúmeros teóricos, dentre os quais podemos destacar Jakobson, Halliday, Bakhtin, Benveniste, que buscaram uma definição de gêneros de maneiras diversas as quais não cabem aqui explicitar e inúmeros trabalhos já o fizeram. Entretanto, a partir da teoria semiolinguística e da compreensão de que os discursos se manifestam e circulam nos lugares sociais, Charaudeau (2004) traz uma nova perspectiva para a análise do gênero discursivo.

Charaudeau (2004) defende a ideia de que todo texto é heterogêneo e, como tal, não é ele que deve ser categorizado, mas aquilo que compõe sua estrutura. A própria Teoria Semiolinguística transforma a noção de análise do ato de linguagem, chamando a atenção para a necessidade de se investigar o sujeito como social e individual ao mesmo tempo, lugar onde se desenvolvem os discursos. Assim, um ato de linguagem só pode ser analisado considerando sua parte linguística e sua parte extralinguística, como lembra Machado (2006). Além disso, todo ato de linguagem está inserido em um contrato de comunicação que envolve os aspectos comunicacional, psicossocial e intencional.

A tendência semiodiscursiva, desse modo, leva em consideração tanto a ancoragem social como a atividade linguageira para a configuração da organização do discurso, mas entende que "tentar classificar os textos a partir da recorrência das marcas formais traz outros tipos de problemas" (CHARAUDEAU, 2004, p. 17). Charaudeau (2004) cita pelo menos dois problemas: a polissemia relacionada aos sentidos das formas; e a não garantia da especificação dos tipos de textos pelas recorrências formais. Dessa maneira, Charaudeau (2004, p. 19) explica que "a questão fundamental que é colocada é a das restrições e da liberdade que o sujeito falante dispõe. Aceitar que existem gêneros é reconhecer que a produção linguageira é submetida a restrições.".

As restrições nas situações de comunicação se originam da identidade dos sujeitos parceiros e do lugar de troca entre eles, além da finalidade ou propósito do discurso (CHARAUDEAU, 2004). Já a discursivização é o espaço das maneiras de dizer e também das restrições discursivas na ordem das atividades de ordenamento do discurso e das restrições formais como maneiras próprias de dizer em determinada situação (CHARAUDEAU, 2004). Em consequência disso, surgem as "visadas discursivas" a partir da intencionalidade psico-socio-linguageira ou propósitos que determinam a expectativa (enjeu) do ato de linguagem 
e a própria troca entre os parceiros. De acordo com Charaudeau (2004, p. 23), "as visadas correspondem, assim, a atitudes enunciativas de base que encontraríamos em um grande corpus de atos comunicativos reagrupados em nome de sua orientação pragmática, mas além de sua ancoragem situacional".

As visadas, de acordo com Vale (2014), são uma ponte entre a finalidade e a intencionalidade do sujeito falante. Dessa maneira, podem ser consideradas como hipóteses sobre a ação da instância de produção. Sendo assim, uma mesma finalidade pode se compor de uma ou mais visadas discursivas. Charaudeau (2004) adverte que essas visadas não são simples abstrações esquemáticas de um texto, nem simplesmente atos de fala ou funções de linguagem e não podem ser consideradas como tipologização dos textos.

\subsection{O contrato do discurso político no corpus: restrições situacionais e discursivas}

A partir das noções de Charaudeau (2006), podemos verificar que o discurso de Dilma Rousseff se encontra no lugar de decisão e de ação, em busca de legitimidade para manter sua autoridade e credibilidade na gestão. De maneira implícita, o seu discurso dedica-se a justificar decisões ou ações para defender sua legitimidade e a conclamar o consenso social para a obtenção de apoio dos cidadãos por meio de estratégias de persuasão e sedução. Por outro lado, o discurso de Aécio Neves, também no lugar de governança, pode ser visto, conforme as explicações de Charaudeau (2006, p. 56), como uma busca pelo "poder de fazer pensar", movido pelas mesmas motivações da presidente, ou seja, também busca legitimidade, a fim de ocupar o lugar de gestão, de autoridade e de credibilidade. Por isso, Aécio Neves dedica-se em seu discurso a criticar as ideias do partido adversário e da presidente que o representa em busca de reforçar sua posição e também conclamar o apoio dos cidadãos por meio de estratégias argumentativas.

Relacionando os dados às circunstâncias de realização do discurso, é preciso ressaltar que os discursos de Aécio Neves e de Dilma Rousseff parecem constituir-se como discursos prévios à campanha eleitoral, mas que se apropriariam da máquina empresarial e da máquina pública para levarem vantagem como pré-candidatos. Percebe-se a tentativa clara de persuadir os cidadãos-eleitores de suas ideias antes do período eleitoral. 
Isso é feito de forma legal, mas apontando, implicitamente, uma vantagem desses políticos em relação aos demais com o mesmo intuito eleitoral.

\subsubsection{Opinião no Portal Folha e Café com a Presidenta}

A seção Opinião faz parte da composição do portal Folha UOL e apresenta a subseção Colunistas que tem o propósito de estimular o debate sobre os problemas brasileiros e mundiais e de refletir as diversas tendências do pensamento contemporâneo com textos de diversos autores de variados setores da sociedade que escrevem de forma regular em dias definidos. Aécio Neves tem seus artigos publicados uma vez por semana, sempre às segundas-feiras, nessa subseção. A página em que são disponibilizados os textos de Aécio Neves se intitula Colunistas, seguida do nome do autor e nela podemos ter acesso aos arquivos de seus textos. As páginas referentes aos textos publicados apresentam os recursos do hipertexto com opções para acessar outras seções da Folha e para interagir com o texto a partir da opção "Comentários", além da possibilidade de compartilhamento pelas redes sociais, impressão e audição do texto.

Já o portal Café com a Presidenta divulga o programa de rádio com o mesmo nome veiculado uma vez por semana. Apresenta um simulado de entrevista entre a presidente Dilma Rousseff e o jornalista Luciano Seixas em que parece ser bastante provável uma montagem da fala do radialista e das respostas da presidente. O programa radiofônico tem duração de seis minutos e são expostos ao cidadão brasileiro os projetos do governo e suas ações em áreas de interesse nacional, como educação, saúde, segurança, entre outros. O portal também apresenta as características do hipertexto com diversas conexões dos itens de informação e possibilidade de compartilhamento, exigindo do leitor algumas competências de leitura na internet, embora isso não dificulte o acesso aos textos por meio do ícone: “Arquivos". O programa é produzido pela Diretoria de Serviços da Empresa Brasil de Comunicação (EBC) e tem supervisão editorial da Secom.

\subsubsection{Configuração dos textos de Aécio Neves}

No que diz respeito à organização formal dos textos, as colunas de Aécio Neves podem ser configuradas a partir da complexidade dos gêneros como instância enunciativa de origem externa, como explica Charaudeau (2012b). Os discursos mostram análises de acontecimentos 
e opinião emitida como político engajado não em uma análise objetiva dos fatos, mas na expressão de seu ponto de vista partidário. Assim, seus textos se apresentam com a estrutura do gênero jornalístico, reconhecidamente pelas relações sociais como artigos de opinião, por buscarem o convencimento do outro de seus ideais políticos a partir da argumentação ou do modo de organização argumentativo, conforme expõe Charaudeau (2012a).

Nesse sentido, as colunas de Aécio Neves, por demonstrarem a visada de "incitação" - no sentido de "fazer acreditar" pela persuasão e a visada de "informação", expressando legitimação para sua tomada de posição ("deve saber"), corroboram para a definição do gênero argumentativo artigo de opinião. Charaudeau (2012a) defende que nesse modo de organização existe como procedimento uma perspectiva de razão demonstrativa de sustentação das afirmações realizadas e de razão persuasiva por meio da apresentação de provas e argumentos consistentes que justifiquem as proposições sobre o mundo.

Podemos caracterizar, dessa maneira, em linhas gerais, o gênero artigo de opinião adotado por Aécio Neves pela relação dialógica e de alteridade; pela presença de uma situação polêmica de debate social; pelos modos de encadeamento; pelas modalidades ou condições de realização e pelo escopo do valor de verdade, conforme a definição de Charaudeau (2012a). Além disso, os artigos evidenciam os procedimentos da lógica argumentativa ou modos de raciocínio de dedução; explicação; associação; escolha alternativa; e escolha restritiva, como podemos constatar nas análises feitas.

Como gênero discursivo, os artigos de opinião analisados estão inseridos numa atividade comunicacional com alguns critérios bem definidos, os quais foram expostos por Charaudeau (2004), dentre os quais destacamos, a partir das análises feitas:

i. A finalidade: os artigos apresentam como visadas predominantes, a visada de "incitação" na busca de fazer crer que o sujeito comunicante age para o bem do destinatário e a visada de "informação" na intenção de "fazer saber" por meio do reconhecimento dos fatos e a capacidade de julgamento. Tem como objetivo promover a adesão do sujeito interpretante a partir da argumentação. Nesse sentido, a informação está a serviço da incitação de maneira inter-relacionada. 
ii. A identidade dos sujeitos: nos artigos, estão bem definidos os papéis do sujeito comunicante Aécio Neves, vinculado à instância política, por intermédio da instância midiática, interessado em investir no cargo de presidente da república. $\mathrm{O}$ sujeito interpretante, como instância cidadã, são os leitores do jornal ou internautas interessados em conhecer a opinião do político, também intermediados pela instância midiática.

iii. O propósito e sua estruturação temática: os temas dos artigos estão relacionados a acontecimentos do espaço público com o propósito de argumentar em favor do bem-estar dos brasileiros e da nação. A temática gira em torno da responsabilidade na gestão, ética e economia.

iv. As circunstâncias: a condição material dos textos é constitutiva do discurso e das colunas publicadas semanalmente no portal da Folha de S. Paulo e representam a localização e o tempo do discurso.

Assim, percebemos no corpus uma argumentação voltada para a problematização dos propósitos, na tentativa de elucidar e avaliar os aspectos do tema em questão, com uma avaliação voltada para os problemas enfrentados pelo país e para a responsabilização do governo no poder. Não há, desse modo, uma avaliação sob diferentes aspectos, o que seria mais apropriado para o gênero artigo de opinião.

\subsubsection{Configuração dos textos de Dilma Rousseff}

Os textos de Dilma Rousseff, na mesma perspectiva da teoria semiolinguística, são portadores de algumas especificidades. Reproduzidos em outro suporte (Portal Café com a Presidenta) o gênero entrevista conservou certas regularidades do discurso jornalístico, apesar da mudança de perfil do veículo, uma vez que está dentro do espaço de governança. $\mathrm{O}$ entrevistador, nesse caso, organiza a maneira de apresentar a entrevista com uma sequência de perguntas pré-determinadas em que não há a presunção de colocar à disposição da opinião pública julgamentos e análises que revelem um verdadeiro engajamento do entrevistado.

Por esse motivo, configurar os textos de Dilma Rousseff como entrevistas propriamente ditas é bastante problemático. Por isso, preferimos adotar o termo "entrevistas simuladas" na expectativa de 
fazer compreender as visadas presentes. Ao passarem para o gênero escrito no ciberespaço, apesar de manter as características do gênero falado, mudam-se as relações entre os interlocutores. De certo modo, as entrevistas simuladas analisadas, conservando as marcas orais, são construídas com algumas marcas do suporte rádio, veículo inicial dos textos, com uma relação de intimidade e conivência intelectual, que foram apontadas por Charaudeau (2012b) como próprias desse suporte.

Da mesma maneira que consideramos os artigos de opinião uma atividade comunicacional com alguns critérios bem definidos, no gênero entrevista também podem ser encontrados alguns critérios que convocam as visadas discursivas, conforme descrevemos:

i. A finalidade: nas entrevistas predominam a visada de "incitação" na busca de fazer acreditar que o sujeito enunciador age para o bem dos destinatários e a visada de "informação", demonstrando o saber de reconhecimento dos fatos e a capacidade de julgamento. Tem como objetivo promover a adesão dos destinatários a partir da argumentação. No caso de Dilma Rousseff, percebemos que o seu discurso tem a finalidade de demonstrar sua capacidade em conhecer a realidade do país e de saber como agir diante das principais exigências da sociedade.

ii. A identidade dos sujeitos: estão bem definidos os papéis do sujeito comunicante Dilma Rousseff como presidente da república, com certo poder de decisão e de ação, vinculada à instância política intermediada pela instância midiática. Como sujeitos interpretantes, temos o interpretante intermediário (falso entrevistador) ao qual ela se dirige diretamente com o objetivo de chegar aos outros sujeitos interpretantes, ouvintes do programa de rádio ou internautas, interessados em conhecer as ações do governo pelas transcrições do portal, na instância cidadã, também intermediada pela instância midiática.

iii. O propósito e sua estruturação temática: os temas das entrevistas estão relacionados aos programas do governo para os cidadãos com o objetivo de demonstrar sua capacidade de gestão. As entrevistas simuladas políticas presumem colocar à disposição da opinião pública as análises da presidente que justificam suas ações no governo envolvendo educação, saúde, moradia, agricultura, dentre outros. 
iv. As circunstâncias: são bem definidas as circunstâncias de espaço e de tempo, ou seja, publicações semanais de transcrições de entrevistas do programa de rádio Café com a Presidenta no portal com o mesmo nome.

Podemos perceber no portal Café com a Presidenta, assim como no Folha, características da comunicação moderna digital, com uma página bastante interativa, que dá a possibilidade de leitura de arquivos das entrevistas e sua audição assim como o compartilhamento em redes sociais, embora não haja espaço para comentários a não ser pelo "Fale conosco". Lembramos que originalmente os textos fazem parte do programa Café com a Presidenta transmitido pelo rádio em rede nacional, conforme já descrevemos.

\section{Estratégias Argumentativas: o ethos no discurso político de Aécio Neves e de Dilma Rousseff}

Tratamos, nesta seção, das estratégias particulares de argumentação que se encontram no corpus, buscando analisar como os sujeitos procuram resolver o problema de saber "como ocupar o espaço de fala" (CHARAUDEAU, 2005), a partir da legitimação e/ou justificativa de sua "tomada de palavra". No modo de organização argumentativo, percebemos, no que diz respeito aos discursos analisados, a tentativa de enfatizar alguns temas de relevância no país. Aécio Neves argumenta sobre temas mais relacionados à gestão pública envolvendo a economia, enquanto que Dilma Rousseff prioriza as questões sociais envolvendo seu governo.

Assim, identificamos como principais teses de Aécio Neves a falta de ética, de responsabilidade, a crise econômica provocada pela má gestão e o uso de artimanhas do governo atual para mascarar os riscos das contas públicas. Dilma Rousseff, por sua vez, tem como principal tese: o governo federal dá respostas às necessidades da população nas questões sociais de saúde com o Mais Médicos, o Minha Casa Minha Vida, o Pronatec e outros programas de seu governo.

A escolha dos conteúdos apresentados é justificável, considerando o contexto de produção, circulação e recepção dos textos. Aécio Neves procura atingir mais o público de classe média e alta, destinatários idealizados do jornal, embora por ser um portal da internet, seja acessível 
a todos. Dilma já tenta idealizar um público-destinatário de classes menos favorecidas as quais se beneficiam dos programas sociais do governo federal. No discurso de Aécio Neves, por exemplo, foram encontradas 97 referências ao campo semântico: Brasil, país e brasileiros, mas não foram encontradas palavras referentes a políticas públicas de geração de emprego, renda, inclusão social e ao povo que são predominantes no discurso de Dilma Rousseff. As únicas ocorrências presentes foram com as palavras "pobres" (duas vezes), "povo" (uma vez), "justiça social" (uma vez), "bem comum" (uma vez) e "emprego" (uma vez) num total de dezoito textos analisados.

Como prática social, a política envolve relações simbólicas e articulação de opiniões em busca de um consenso por meio de estratégias discursivas. É preciso, nesse contexto, que o político transmita uma imagem de confiança, de admiração, para que mascare seu desejo pessoal de poder. As estratégias discursivas utilizadas pelos políticos, desse modo, dependem de sua identidade social, da maneira como ele percebe a opinião pública e das escolhas que faz para se chegar a ela, além da posição de outros atores políticos, como explica Charaudeau (2006). Na construção da imagem de si "o ethos político deve, portanto, mergulhar nos imaginários populares mais amplamente partilhados, uma vez que deve atingir o maior número, em nome de uma espécie de contrato de reconhecimento implícito" (CHARAUDEAU, 2006, p. 87).

\subsection{A encenação argumentativa no corpus}

$\mathrm{Na}$ encenação argumentativa, o sujeito utiliza determinados procedimentos ou componentes que podem ser semânticos, discursivos e de composição. O dispositivo argumentativo, assim, como já expusemos, faz uso da asserção e do encadeamento de asserções, chamada de proposta, a partir de uma tomada de posição, ou proposição, sendo fundamental, de acordo com Charaudeau (2012a), o desenvolvimento da persuasão.

Os procedimentos semânticos fazem parte da utilização de argumentos de um consenso social em que os membros de determinado grupo compartilham valores (CHARAUDEAU, 2012a), em domínios de avaliação especificos. Os Valores estão relacionados aos domínios de avaliação e representam as normas de representação social construídas em cada um desses domínios. Percebemos nos textos analisados a presença 
desses procedimentos semânticos fundamentando a argumentação em busca do compartilhamento de valores.

Os procedimentos discursivos baseiam-se na aplicação casual ou sistemática de certas categorias da língua ou procedimentos de outros modos de organização do discurso com o objetivo de promover a persuasão, de acordo com Charaudeau (2012a). O autor (2012a) enfatiza a definição; a comparação; a citação; a descrição narrativa; a reiteração e o questionamento; os quais passamos a considerar na análise do discurso no corpus.

\subsubsection{A definição}

A definição com fins argumentativos auxilia na produção de efeitos de evidência e de saber para o indivíduo que a utiliza em sua argumentação, segundo Charaudeau (2012a). Para o autor, existem dois tipos de definição: i. definição de um ser, por meio de distinções de sentido em torno de uma noção, de recurso à propriedade dos termos ou de falsa tautologia; e ii. a definição de um comportamento.

A presença de milhares de brasileiros nas ruas, um coro de vozes que ainda ecoa a espera de respostas, é o retrato emblemático e inesquecível do ano que se encerra. (Aécio Neves, Feliz Brasil Novo, 30/12/2013)

[...] fizemos o Programa Caminho da Escola, que são os ônibus amarelinhos, para garantir que as crianças das áreas rurais e dos municípios do interior cheguem mais rápido, com maior segurança e conforto à sala de aula. Hoje, sabe, Luciano, já são 17 mil ônibus só no meu governo. (Dilma Rousseff, Dilma: Educação é o passaporte para o futuro do Brasil, 06/01/2014)

Nesses fragmentos notamos a presença da qualificação de traços semânticos que caracterizam as manifestações ocorridas no Brasil no ano de 2013, na visão do político Aécio Neves. Dilma Rousseff, por sua vez, caracteriza o "Programa Caminho da Escola". Apesar dos fragmentos não constituírem uma verdadeira definição, tomam uma aparência da mesma, conforme a definição de Charaudeau (2012a), produzindo um efeito de evidência e de saber. 


\subsubsection{A comparação}

Segundo Charaudeau (2012a), o recurso à comparação visa a reforçar uma evidência, produzindo, se for objetiva, um efeito pedagógico ao buscar melhorar o processo de compreensão de um dado; ou um efeito de ofuscamento, se for subjetiva, na tentativa de desviar a atenção do interlocutor para outro fato semelhante, sem que se examine a validade da prova. Os trechos abaixo ilustram esse procedimento discursivo:

O isolamento nunca fez bem aos governantes. Quem se afasta do contato popular e confia apenas num séquito de aduladores, tende a desenvolver, na clausura do poder, uma aversão crescente à realidade. [...] Temo que estejamos vivendo algo semelhante no Brasil. (Aécio Neves, O lugar da politica, 17/03/2014) - comparação por semelhança

Você, jovem, sabe o quanto o seu padrão de vida melhorou comparado ao que você tinha na infância e ao que seus pais tinham na sua idade. Usem essa fotografia do presente e do passado recente como pano de fundo para projetar o futuro. (Dilma Rousseff, No pronunciamento à Nação, Dilma afirma que 2014 será ainda melhor para o Brasil, 30/12/2013) - comparação por dessemelhança e comparação subjetiva

É perceptível nos exemplos apresentados acima o interesse dos sujeitos falantes em utilizar a estratégia da comparação para reforçar o julgamento a respeito das respectivas temáticas. Primeiro, Aécio Neves compara o comportamento de isolamento da presidente Dilma Rousseff a outros governantes que se afastam do contato popular e tendem a desenvolver uma aversão à realidade. Dilma Rousseff, por outro lado, explora esse procedimento discursivo para pôr em evidência seus programas de governo, realizando uma comparação por dessemelhança ao relacionar o passado e o presente dos jovens numa posição de desigualdade. No mesmo exemplo, percebemos também o uso da comparação subjetiva por meio de uma analogia com a finalidade de produzir uma evidência: "Usem essa fotografia do presente e do passado recente como pano de fundo para projetar o futuro". 


\subsubsection{A descrição narrativa}

A descrição narrativa refere-se ao processo de descrever fatos para reforçar provas ou produzi-las. Como efeito, ela pode funcionar para exemplificar argumentos selecionados e nisso se diferencia da comparação. Nos discursos analisados, observamos esse procedimento principalmente nas críticas que Aécio Neves faz ao governo Dilma e em referências a personalidades importantes como Nelson Mandela, Papa Francisco, Tancredo Neves etc. para realçar seu ponto de vista a respeito da política brasileira. Dilma Rousseff utiliza a descrição narrativa basicamente para dar ênfase aos resultados de seus programas de governo citando exemplos de pessoas que foram beneficiadas por eles. Este recurso discursivo é adotado em todos os seus textos. Selecionamos os exemplos a seguir:

O impressionante na obra de Mandela não é apenas o que ele foi capaz de fazer, mas como o fez. Foi surpreendente e exemplar a sua posição pacificadora, superando ressentimentos naturalmente existentes sobre um regime que roubou parte importante da sua vida, encarcerando-o injustamente por quase três décadas, e dominou o seu país, dividindo-o em privilégios e castas, opressores e oprimidos, brancos e negros, ricos e pobres, mantendo milhares subjugados pelo execrável apartheid. [...] (Aécio Neves, Mandela, 09/12/2013)

O Ian é um garoto muito batalhador, que sempre teve o sonho de estudar no exterior. Ele foi aluno, Luciano, de uma escola pública a vida toda, se esforçou muito para tirar uma boa nota no Enem e conseguiu, sim, uma vaga no curso de Sistemas de Informação na Universidade Federal da Bahia. Lá na universidade, o Ian soube do Ciência sem Fronteiras e viu nele a grande chance de realizar seu sonho. Então, ele fez a inscrição no Ciência sem Fronteiras e conseguiu a bolsa para passar um ano na Universidade do Estado de Nova Iorque, nos Estados Unidos. (Dilma Rousseff, Ciência sem Fronteiras vai oferecer bolsas para o mestrado profissional no exterior, $02 / 12 / 2014$ ) 
Podemos notar que os exemplos mostrados ilustram a utilização do procedimento discursivo da descrição narrativa por meio da descrição de fatos (Aécio Neves) ou pela narração de uma pequena história (Dilma Rousseff). Percebemos que as descrições servem para o desenvolvimento do raciocínio por analogia, produzindo um efeito de exemplificação, conforme descreve Charaudeau (2012a). Aécio Neves, ao trazer personagens importantes, como Nelson Mandela, tenta relacioná-los como modelos para o mundo e dá a entender que os políticos deviam seguir seus exemplos na busca de um mundo melhor.

Dilma Rousseff, diferentemente, ao trazer personagens do povo procura exemplificar o sucesso de seus programas de governo, como o "Ciência sem Fronteiras" de uma forma mais simples, mais ilustrativa, adotando uma linguagem de mais fácil compreensão pelo grande público, uma forma de "explicar melhor", como elucida Charaudeau (2012a, p. 239) a respeito desse procedimento. Ao mesmo tempo, ao contar uma experiência de uma pessoa do povo, Dilma Rousseff procura reforçar a prova de que os programas de seu governo servem para o bem-estar da população menos favorecida, enfatizando, assim, em seu discurso, sua prioridade em questões sociais.

\subsubsection{A citação}

Outro procedimento discursivo caracterizado por Charaudeau (2012a) é a citação. Considerado fenômeno linguístico é denominado pelo autor como discurso relatado. A citação, nesse sentido, relaciona-se à referência aos dizeres de outros sujeitos a fim de conferir à argumentação traços de autenticidade (CHARAUDEAU, 2012a). Podemos perceber, assim, que a citação é uma prática textual central na argumentação com a finalidade da persuasão, por promover justificativas para argumentos e demonstrar a novidade de uma posição na busca de aceitação. Dessa maneira, os discursos do corpus evidenciam tal procedimento, conforme podemos observar nas seguintes passagens:

"Estamos no limiar de um novo ciclo econômico do Brasil", disse o ministro da Fazenda, para justificar o injustificável. (Aécio Neves, Truques e riscos, 20/01/2014) - de um dizer

A Francisca Roseane, de 16 anos, contou para a gente que, antes do ônibus do Caminho da Escola chegar em Ipu, ela tinha que sair de casa às 5 h30 da manhã para não 
chegar atrasada na aula. (Dilma Rousseff, Caminho da Escola ajuda a combater a evasão escolar em todo o país, 16/12/2013) - de uma experiência

Aécio Neves utiliza as aspas para introduzir a referência ao discurso do outro locutor (ministro da fazenda e Almiro). A citação do dizer, dessa forma, funciona como uma fonte de verdade das declarações, a fim de sustentar seus argumentos. Já Dilma Rousseff procura utilizar a citação para exemplificar o sucesso de seus programas de governo (Caminho da Escola), por meio do discurso indireto como testemunho de um dizer, nos termos de Charaudeau (2012a). Da mesma forma que Aécio Neves, o discurso tenta referir-se à fala de outros locutores para evidenciar um efeito de autenticidade.

\subsubsection{A acumulação}

Já a acumulação, como a própria denominação já informa, apoiase na reunião de vários argumentos para uma mesma evidência, o que pode ser construído por uma simples acumulação, por uma gradação de argumentos ou uma (falsa) tautologia (CHARAUDEAU, 2012a). Vejamos os exemplos:

Afirmou que a inflação está controlada, quando sabemos -Davos também-que nos últimos três anos a taxa esteve sempre prestes a romper o teto da meta - e defendeu sua política fiscal, hoje conhecida pela "criatividade" de sua contabilidade. Chegou ao cúmulo de dizer que diminuiu a dívida pública bruta de $60,9 \%$ do PIB para $58,4 \%$. (Aécio Neves, No palanque, em Davos, 27/01/2014)-uma gradação

Luciano, além de realizar o sonho da casa própria para milhões de brasileiros, o Minha Casa Minha Vida é importante para todo o país. As obras do programa movimentam toda a economia brasileira, tem casa do Minha Casa Minha Vida espalhada pelo país inteiro. (Dilma Rousseff, Minha Casa Minha Vida já contratou mais de 2 milhões de moradias no governo Dilma, 09/12/2013) gradação 
Os exemplos demonstram a utilização de vários argumentos para servir de uma mesma prova. Assim, Aécio Neves reúne os argumentos "Afirmou que a inflação está controlada quando sabemos - Davos também-que nos últimos três anos a taxa esteve sempre prestes a romper o teto da meta"; "defendeu sua política fiscal"; e "chegou ao cúmulo de dizer que diminuiu a dívida pública bruta", numa gradação a partir da referência às falas da presidente em seu discurso em Davos. Já no discurso de Dilma Rousseff, verificamos que ela constrói a prova de que o Minha Casa Minha Vida está dando certo, a partir da gradação dos argumentos: "além de realizar o sonho da casa própria para milhões de brasileiros, o Minha Casa Minha Vida é importante para todo o país".

\subsubsection{O questionamento}

Como último procedimento discursivo de argumentação, Charaudeau (2012a) descreve o questionamento, em que se busca produzir uma validação de uma hipótese. Tal procedimento é recorrente nos discursos de Aécio Neves, principalmente por meio do questionamento de provocação e de denegação. Dilma Rousseff também utiliza o procedimento, mas como estratégia de verificação do saber, basicamente. Seguem alguns trechos que ilustram esse procedimento discursivo.

Para calcular a inflação, nada melhor que contar com o controle político sobre preços administrados em setores estratégicos. E por que não atrasar a transferência de R\$ 7 bilhões a Estados e municípios, inclusive recursos voltados para a saúde pública, prejudicando milhões de brasileiros, para dar a impressão de que cumpriu-se o superávit primário? (Aécio Neves, Truques e riscos, 20/01/2014)

[...] Onde está a coerência com a atitude adotada na crise paraguaia, em que foi invocada a cláusula democrática do Mercosul? Por afinidades ideológicas, o Brasil está deixando de assumir suas responsabilidades internacionais também na questão dos direitos humanos. (Aécio Neves, Diplomacia à deriva, 24/02/2014)

Podemos perceber que os questionamentos apresentados acima colocam em evidência a proposta argumentativa dos sujeitos falantes. Aécio Neves faz uso do questionamento propondo um argumento que é 
rejeitado antecipadamente por ser prejudicial a milhões de brasileiros, segundo ele. Dilma Rousseff utiliza o questionamento mais com a finalidade de estabelecer uma simulação de diálogo para reforçar os argumentos independentemente da resposta, o que de certo modo torna a entrevista artificial. Essas expressões de questionamento são frequentes em seu discurso.

\subsection{Os ethé de credibilidade}

Na condição de dramatização, Aécio Neves procura construir sua imagem a partir da ideologia do PSDB, enraizada no neoliberalismo e na social democracia, buscando associar-se ao ethos da seriedade e eficiência na gestão pública. Seu discurso centraliza-se no ethos de conduta ideal da política contemporânea, buscando associar-se à figura do homem honrado e preocupado com o bem comum que corresponde a uma virtude moral originada na tradição retórica. O político busca a comoção do público, através de argumentos que retomem momentos críticos ou de crise enfrentados pela sociedade brasileira.

Dessa maneira, na tentativa de se consolidar no ethos de "credibilidade", procura dar suporte à identificação frente ao seu interlocutor e possível eleitor. Destacamos também que, em sua dramatização, o senador e pré-candidato critica diretamente o governo do partido adversário. Apesar de usar um discurso bastante formal, o discurso de Aécio Neves é compreensível ao grande público.

A presidente e pré-candidata à presidência situa-se, por sua vez, diretamente, como parte do grupo de políticos responsáveis por mudanças que começaram a ocorrer no país, a partir do momento em que o ex-presidente Lula foi eleito. É perceptível em seu discurso, essa relação com o ex-presidente como sendo do mesmo grupo do qual faz parte, numa referência à inteligência e bom senso, que culminaram em um governo feito para "todos os brasileiros", como podemos verificar no lema de seu governo. Trabalha, dessa forma, a construção de sua imagem de competente e de acordo com a ideologia do PT, com raízes na visão socialista-democrática, com traços do populismo e do marxismo.

A presidente Dilma Rousseff em seu discurso prioriza bastante a figura da mulher, pela sua própria condição feminina e pelo fato de poucas mulheres terem um cargo tão importante como a presidência do país. Assim, sua estratégia discursiva explora bastante a figura maternal e 
pioneira que constrói em seu ethos e se situa sempre ao lado do cidadão. Ela valoriza a construção de uma identidade discursiva baseada em sua condição de eficácia como presidente da república, sua condição de sinceridade e transparência com capacidade de honrar suas promessas e atingir os objetivos propostos.

Considerando o fato de serem políticos de partidos rivais, PSDB e PT, respectivamente, com uma disputa histórica de interesses e ideologias no campo de seus discursos, podemos observar que os sujeitos políticos procuram estabelecer alguns públicos destinatários mais precisos, como os da classe mais baixa por parte da presidente Dilma e um destinatário mais geral, por Aécio Neves. Nota-se uma tendência a um apelo pelo Partido dos Trabalhadores à classe operária, ou à massa popular, enquanto que o PSDB visa a um público destinatário mais amplo, envolvendo setores mais da elite. Tanto no discurso de Aécio Neves, como no de Dilma Rousseff, podemos notar a busca por um ethos ao mesmo tempo voltado para si mesmo, para o cidadão e para os valores de referência, explicitados por Charaudeau (2006).

Em se tratando dos discursos em análise neste estudo, podemos perceber tanto no discurso de Aécio Neves quanto no de Dilma Rousseff que há todo um trabalho em conjunto dos sujeitos dos discursos bem como de seus assessores e profissionais da mídia para que suas identidades discursivas e sociais sejam fundidas na encenação do discurso. Na medida em que o ethos se relaciona com as representações sociais, ele passa a significar o entrecruzamento de julgamentos dos indivíduos de um grupo social na busca de ser aceito pelos interlocutores.

\section{Considerações finais}

O presente artigo pretendeu apresentar um recorte da pesquisa realizada com o objetivo de analisar, a partir da teoria Semiolinguística de Análise do Discurso (CHARAUDEAU, 2001; 2012a), como o discurso político prévio à campanha eleitoral de Aécio Neves e Dilma Rousseff está relacionado aos fenômenos psicológicos e sociais envolvendo o contrato de comunicação de ambos os políticos. Por meio da análise e comparação entre os discursos, foi possível descrever a organização argumentativa e a construção do ethos em textos publicados na Folha de S. Paulo e no programa Café com a Presidenta, no período de dezembro de 2013 a março de 2014, destacando as características dos fatos de 
linguagem. Foi possível também compreender a constituição do discurso político como fato social num espaço de estratégias e restrições.

Ao nos propor a realizar este trabalho de pesquisa, almejávamos que pudéssemos conhecer as principais características do discurso político na sociedade atual e, de fato, comprovamos que o discurso político é o resultado de uma interação complexa entre discursos e de um encontro entre a instância política e a instância cidadã por intermédio da instância midiática (CHARAUDEAU, 2006). Percebemos que, ao construir seus discursos, tanto Aécio Neves como Dilma Rousseff interessam-se pelos discursos fabricados pela opinião pública e têm um olhar atento às representações sociais e crenças. Aécio Neves, mais voltado para o discurso neoliberal, constrói seu ethos com base no engajamento em seu papel de político interessado em transformar a situação atual vivida pelo país, a parir de um ethos de competência e eficácia na gestão da vida política.

O político utiliza argumentos que tendem a desmoralizar a gestão do Partido dos Trabalhadores (PT) para construir o modelo do saberfazer de seu discurso. Verificamos que Aécio Neves procura mostrar uma imagem de competência e vontade de agir, estudados na retórica antiga e outras teorias argumentativas. Podemos notar que as estratégias discursivas adotadas por Aécio Neves buscam atrair a atenção dos destinatários com base em julgamentos das ações do governo federal e na desqualificação destas, numa forma de contrato de reconhecimento implícito de imaginários partilhados socialmente.

Dilma Rousseff, por sua vez, constrói um ethos de competência voltado para si mesma, ligado à enunciação de sua identidade social, ao mesmo tempo em que permite a construção de uma imagem, para alguns destinatários, de um ethos não desejado por se tratar de um discurso um tanto artificial em se tratando de entrevistas. Enquanto cenário de confrontos de ideologias ou como meio de persuasão pela argumentação, seu discurso demonstra vontade de agir e eficácia de suas ações como presidente da república. Nesse sentido, é perceptível um discurso que vai ao encontro das expectativas do povo brasileiro, principalmente das camadas mais populares, o que leva a atingir os objetivos de sua encenação argumentativa.

Além disso, Dilma Rousseff constrói a imagem de credibilidade que expressa o poder fazer com sinceridade, performance e eficácia. Dessa maneira, observamos que, a partir da retomada de certos imaginários 
sociodiscursivos, Dilma Rousseff consegue exercer certa influência sobre os cidadãos ao demonstrar conhecer as regras da insinceridade e do mentir verdadeiro no contexto da modernidade, apesar de a própria estrutura de seus textos (entrevistas simuladas) trazerem certa superficialidade. Assim, tenta sobrepor uma imagem de gestora eficiente não entrando em questões que envolvem escândalos de corrupção que acometeram seu governo no PT. O que percebemos é uma tentativa implícita de propor uma mudança ligada à continuidade.

Conforme o exposto, podemos confirmar nos discursos analisados de Aécio Neves e de Dilma Rousseff que a prática política nos dias atuais, principalmente em países capitalistas como o nosso, revela um lugar de exercício de poder e de influência com uma preocupação muito grande com a repercussão que possam trazer os seus discursos. Por meio de valores simbólicos que projetam um ideal social, são fabricadas imagens que tornam o ethos mais importante que o logos (CHARAUDEAU, 2006). De uma maneira geral, "não é mais o conteúdo das ideias que é dado a entender, mas sua encenação" (CHARAUDEAU, 2006, p. 307).

Percebemos também que tanto o discurso de Aécio Neves como o de Dilma Rousseff constituem-se como discursos prévios à campanha eleitoral que se apropriam da máquina empresarial e da máquina pública para levarem vantagem, na medida em que tentam persuadir os cidadãoseleitores antes do período eleitoral. Por fim, destacamos que prevalece nos dois discursos a opinião voltada para as imagens de credibilidade e para as estratégias de encenação que, nos dias atuais, embora levem a certa insatisfação geral, não diminuem a importância e funcionalidade social do discurso político tornando sua análise cada vez mais instigante e desafiadora.

\section{Referências}

ARISTÓTELES. A política. São Paulo: Folha de S. Paulo, 2010. (Coleção Folha: livros que mudaram o mundo, v. 11).

CHARAUDEAU, P. Uma teoria dos sujeitos da linguagem. In: MARI, H. et alii. Análise do discurso: fundamentos e práticas. Belo Horizonte: UFMG, 2001. p. 23-38. 
CHARAUDEAU, P. Visadas discursivas, gêneros situacionais e construção textual. In: MACHADO, I. L.; MELLO, R (Org.). Gêneros: reflexões em análise do discurso. Belo Horizonte, NAD/FALE-UFMG, 2004. p. 13-42.

CHARAUDEAU, P. Uma análise semiolinguística do texto e do discurso. In: PAULIUKONIS, M. A. L.; GAVAZZI, S. (Org.). Da língua ao discurso: reflexões para o ensino. Rio de Janeiro: Lucerna, 2005. p. 1127. Disponível em: $<$ http://www.patrick-charaudeau.com/Uma-analisesemiolinguistica-do.html>. Acesso em: 1 jun. 2013.

CHARAUDEAU, P. Discurso politico. Trad. Fabiana Komesu e Dilson Ferreira da Cruz. São Paulo: Contexto, 2006.

CHARAUDEAU, P. Linguagem e discurso: modos de organização. 2. ed. São Paulo: Contexto, 2012a.

CHARAUDEAU, P. Discurso das mídias. 2. ed. São Paulo: Contexto, 2012 b.

MACHADO, I. L. Uma teoria de análise do discurso: a semiolinguística. In: MARI et alii. (Org.). Análise do discurso: fundamentos e práticas. Belo Horizonte: Núcleo de Análise do Discurso, FALE/UFMG, 2001. p. 39-62.

MACHADO, I. L. Algumas reflexões sobre a teoria semiolinguística. Revista Letras\&Letras, Uberlândia, v. 22, n. 2, p. 13-21, jul.-dez. 2006. Disponível em: $<$ http://www.seer.ufu.br/index.php/letraseletras/article/ view/25229/14044>. Acesso em: 3 abr. 2014.

MACHADO, I. L. Teoria e discursos transgressivos. Revista Estudos da Linguagem, Belo Horizonte, v. 15, n. 1, p. 109-128, jan.-jun., 2007. Disponível em: <http://relin.letras.ufmg.br/revista/english/upload/07Ida-Lucia.pdf>. Acesso em 3 abr. 2014.

MELO, M. S. S. Pressupostos de uma teoria psicossocial do discurso: a semiolinguística. In: GOMES, M. C. A.; MELO, M.S.S.; CATALDI, C. (Ed.). Gênero discursivo, mídia e identidade. Viçosa: Ed. UFV, 2007. p. 105-114.

MENDES, P. H. A. Sobre o contrato de comunicação: do discurso ao debate político eleitoral. In: MARI, H. et alii. (Org.). Análise do discurso: fundamentos e práticas. Belo Horizonte: Núcleo de Análise do Discurso, FALE/UFMG, 2001. p. 313-346. 
PERELMAN, C.; OLBRECHTS-TYTECA, L. Tratado de argumentação. Trad. Maria Ermantina de Almeida Prado Galvão. 2.ed. São Paulo: Martins Fontes, 2005.

SOUZA, W. E. Retórica, Argumentação e discurso. In: MARI, H. et alii. (Org.). Análise do discurso: fundamentos e práticas. Belo Horizonte: Núcleo de Análise do Discurso, FALE/UFMG, 2001. p. 156-199.

VALE, R. P. G. Intencionalidade, finalidades e visadas na análise do discurso humorístico. DLCV, UFPB, v. 11, n. 1, 2014, p. 137-161. 